ADMHNISTRATIVAS

Delegação de Podêres a Instituições Autônomas

Câo TÁcrto.

Nos

os relatórios apresentados pela Seção Brasileira às Mesas-Redondas de Opatija (1957) e Liège (1958) foi examinądo o processo de descentralização administrativa no Brasil, de acôrdo com os questionários elaborados pelos respectivos relatores gerais.

As contribuições oferecidas, na oportunidade, pelo DR. Antônio GoNÇALVES DE OLIVEIRA e pelo autor do presente trabalho informaram, amplamente, sôbre o regime das autarquias, sociedades de economia mista e fundações, no direito brasileiro, como formas de execução do serviço público por meio de entes personalizados e autônomos.

O atual estudo constitui um desenvolvimento dêsses ensaios precedentes, visando a esclarecer, especialmente, os pontos a serem focalizados no XI Congresso Internacional de Ciências Administrativas, de acôrdo com a nota previa do respectivo relator geral.

Serão, assim, examinados, apenas, os aspectos de delegação de podêres do Estado a organismos profissionais (excluidos os sindicatos e organizações artesanais) @ a universidade, assim como o regime administrativo e financeiro dessas instituições.

\title{
ORGANISMOS PROFISSIONAIS
}

A Constituição Federal assegura o livre exercicio de qualquer profissăo, observadas as condições de capacidade que a lei estabelece (art. 141, $\S 14)$.

Admitindo a noção relativa dos direitos públicos subjetivos, o texto constitucional condiciona a liberdade profissional dos brasileiros e estrangeiros residentes no país à garantia do bem público. A lei, regulando as condiçóes de capacidade, sujeita o desempenho lícito das profissões ao poder da polícia do Estado, seja mediante o contrôle dos títulos de habilitação do ensino médio ou superior, sujeito a registro no Ministério de Educação e Cultura, seja pela disciplina e fiscalização das atividades, por intermédio de organismos corporativos. 
São as seguintes as ordens profissionais que, por fôrça de lei, exercem funções delegadas do poder público:

\section{A) Ordem dos Advogados do Brasil}

Foi criada pelo Decreto n. 19.408, de 18 de novembro de 1930 , como órgão de disciplina, defesa e seleção da classe dos advogados, considerando-se como serviço público federal, com imunidade tributária.

A Ordem dos Advogados do Brasil constitui-se de seções, no Distrito Federal e em cada Estado e Território Federal, com personalidade juridica própria e autonomia administrativa, geridas por um Conselho Secional e Diretoria, com a manifestação, em certos casos, da Assembléia Geral dos advogados inscritos. O Conselho Federal, órgão de jurisdição nacional, composto de representantes dos Conselhos Secionais, elege o Presidente e Secretário-Geral da Ordem, decide os recursos dos atos dos Conselhos Secionais e exerce, em geral, o poder normativo e de supervisão, incumbindo-lhe de votar e alterar o Código de Ética Profissional. Tôdas as funções nos vários órgãos são exercidas a título gratuito.

O exercício da advocacia, em juízo, é privativo dos membros inscritos na seção respectiva, sendo obrigatória a representação das partes por profissional habilitado, salvo no foro criminal, em que o acusado poderá defender-se pessoalmente.

Para a inscrição no quadro de advogados da Ordem é necessário, além dos requisitos de capacidade civil, ser bacharel ou doutor em direito, com diploma registrado no Ministério de Educação e Cultura, e não estar impedido do exercício da profissão, em virtude de condenação criminal ou outra proibição legal. Os estrangeiros sòmente poderão ser registrado em caso de reciprocidade no respectivo país de origem e mediante revalidação do diploma estrangeiro.

Nas comarcas, têrmos ou distritos judiciários onde não sejam domiciliados mais de três advogados diplomados, poderão ser inscritos, a titulo precário, pelo prazo de três anos, provisionados ou solicitadores, sujeitos a em exame de suficiência e habilitados a práticas de certos atos forenses. Os alunos do penúltimo ano do curso de Direito poderão, também, obter dos Presidentes dos Tribunais de Justiça cartas de solicitador, sujeitas à inscrição na Ordem dos Advogados.

A fonte principal de receita da Ordem dos Advogados do Brasil é constituída pelas taxas anuais e de inscrição recolhidas pelos respectivos membros. A taxa anual atualmente em vigor no Distrito Federal equivale a $1 / 5$ do salário-mínimo mensal na região.

A administração dos bens e valores incumbe à Diretoria e aos Conselhos Seciona:s, mediante fiscalização financeira das assembléias gerais que, anualmente, aprovam as contas do exercício encerrado.

A Ordem dos Advogados não está obrigada à prestação de contas ao Tribunal de Contas da União, porque não recebe tributos, nem gere dinheiros ou bens públicos, conforme decidiu o Tribunal Federal de Recursos, considerando-a como pessoa jurídica de direito público sui generis. 
A Ordem dos Advogados tem função disciplinar, fiscalizando a conduta dos advogados, provisionados e solicitadores e aplicando sanções de advertência, censura, multa, suspensão do exercicio da profissão ou cancelamento da inscrição, que inabilita para a atividade profissional.

Os deveres do advogado estão enumerados no Código de Ética Profissional, aprovado em 25 de julho de 1934, pelo Conselho Federal da Ordem dos Advogados.

A legalidade dos atos praticados pelos órgãos secionais ou federais da Ordem dos Advogados poderá ser apreciada pelo Poder Judiciário, não havendo, porém, qualquer interferência do Poder Executivo em sua administração.

A Ordem dos Advogados é, ainda, órgão de colaboração do poder públiro, devendo participar, obrigatòriamente, do julgamento dos concursos de provas realizados para o ingresso na magistratura vitalícia (Constituição Federal, art. 124, i. III).

\section{B) Conselhos de Engenharia e Arquitetura}

O Decreto n. 23.569, de 11 de dezembro de 1933, regulando o exercício das profissões de engenheiro, arquiteto e agrimensor, criou organismos profissionais, incumbidos de fiscalizar a atividade exercida por pessoas físicas ou jurídicas.

O exercício das profissões acima indicadas, bem como de cargos públicos nas mesmas especialidades, em todo o território nacional, sòmente é permitido a quem fôr portador de carteira profissional expedida pelos Conselhos Regionais de Engenharia e Arquitetura, perante os quais também é obrigatório o registro de técnicos de grau médio ou superior e de auxiliares de Engenheiro.

Sòmente terão valor jurídico os estudos, plantas, projetos, laudos e quaisquer outros trabaihos de engenharia, arquitetura e agrimensura, quer particulareś, quer públicos, inclusive em juizo e nas repartições públicas federais, estaduais e municipais, quando subscritos por profissionais registrados.

Tôdas as obras, construções e instalações terão obrigatòriamente a responsabilidade de profissional habilitado, devendo ser anotados no Conselho Regional os contratos de obras e outros serviços técnicos.

Os individuos, firmas ou sociedades que explorem, embora parcialmente, atividade de engenharia, arquitetura ou agrimensura sòmente poderão funcionar mediante registro, no Conselho Regional, declarando o profissional responsável pela parte técnica dos serviços.

O contrôle profissional é exercido pelo Conselho Federal de Engenharia e Arquitetura e pelos Conselhos Regionais de Engenharia e Arquitetura, que constituem, em seu conjunto, uma autarquia, sendo cada um dêles dotado de personalidade jurídica de direito público (Decreto-lei n. 8.620 , de 10 de janeiro de 1946, art. 1).

O Conselho Federal de Engenharia e Arquitetura é composto de um Presidente, nomeado pelo Presidente da República, de 6 conselheiros escolhidos pelos Conselhos Sindicais e de 3 conselheiros designados, respectiva- 
mente, pelas Congregações da Escola Nacional de Engenharia, Escola de Minas e Metalurgia e Faculdade Nacional de Arquitetura. Os Conselhos Secionais são constituídos em base representativa semelhante à do Conselho Federal. O mandato dos conselheiros será de três anos e a título gratuito.

Além das taxas pela expedição de carteiras e licenças, os Conselhos Regionais arrecadarão dos profissionais e firmas registradas anuidades fixadas em lei (Lei n. 3.097, de 31 de janeiro de 1957), que correspondem à sua receita, parte da qual é destinada ao Conselho Federal.

O Conselho Federal e os Conselhos Secionais, como órgão de defesa e disciplina da classe, julgarão as infrações praticadas pelos profissionais cu firmas, aplicando penas de multas, suspensão ou cancelamento de registro.

A gestão administrativa e financeira dos Conselhos é autônoma, cabendo ao Tribunal de Contas da União o exame e aprovação das respectivas contas Qz ao Poder Judiciário o contrôle jurisdicional da legalidade dos atos administrativos por êles praticados.

\section{C) Conselhos de Medicina}

Os Conselhos de Medicina, instituídos pelo Decreto-lei n. ${ }^{\circ} 7.955$, de 13 de setembro de 1945, foram modificados pela Lei n. 3.268, de 30 de setembro de 1957, pela qual o Conselho Federal, com sede na capital do país e com jurisdição nacional, e os Conselhos Regionais, localizados $\mathrm{cm}$ cada capital de Estado e Território e no Distrito Federal, passaram a constituir, em seu conjunto, uma autarquia, sendo cada um dêles dotado de personalidade jurídica de direito público, com autonomia administrativa e financeira.

Os Conselhos Secionais serão eleitos pela Assembléia Geral, à exceção de um membro escolhido pela associação de classe. O Conselho Federal terá, igualmente, um membro escolhido pela associação de classe e os demais eleitos pelos Conselhos Regionais. Os mandatos são honoríficos e com duração de cinco anos.

O exercício legal da profissão médica, além do prévio registro do diploma no Ministério de Educação e Cultura, depende da inscrição no Conselho Regional de Medicina e expedição da carteira profissional correspondente.

Aos Conselhos de Medicina incumbe fiscalizar o exercicio da profissão e zelar pela ética profissional, de acôrdo com o Código de Deontologia Médica, aprovado pelo Conselho Federal.

Os Conselhos Regionais são mantidos pelas taxas de inscrição e de expedição de carteiras profissionais e pelas antidades e multas pagas pelos médicos inscritos. A renda do Conselho Federal é constituida por $20 \%$ da totalidade do impôsto sindical dos médicos e 1/3 da receita arrecadada pelos Conselhos Regionais.

O Poder disciplinar compreende a aplicação de penas de advertência, censura, suspensão temporária do exercício profissional e cancelamento do quadro.

As contas dos Conselhos de Medicina dependem de aprovação do Tribunal de Contas da União e a legalidade de seus atos fica sujeita ao contrôle do Poder Judiciário. 


\section{D) Conselhos de Contabilidade}

O Decreto-lei n. 9.295, de 27 de maio de 1946, instituiu o Conselho Federal de Contabilidade, de jurisdição nacional, sede no Distrito Federal, e os Conselhos Regionais de Contabilidade, de âmbito local.

Os contabilistas, compreendidos como tais os contadores e guardalivros, sòmente poderão exercer atividade após o registro do diploma no Ministério de Educação e Cultura e a inscrição no Conselho Regional de Contabilidade, que expedirá a respectiva carteira profissional.

Os Conselhos são constituídos mediante eleição, com mandato de três anos, salvo quanto ao Presidente do Conselho Federal de Contabilidade, que é designado pelo Govêrno Federal.

Os trabalhos técnicos de contabilidade judiciais e extrajudiciais são privativos dos portadores de carteira profissional, obrigadas as firmas que operam no ramo a ter, comıs responsável pelos serviços, um profissional habilitado.

Os Conselhos de Contabilidade exercem poder disciplinar sôbre os profissionais inscritos, arrecadam taxas e aplicam multas e suspensões temporárias ou permanentes do exercício da profissão. Estão sujeitos ao contrôle do Poder Judiciário, quanto à legalidade de seus atos e do Tribunal de Contas, com respeito à gestão financeira.

\section{E) Conselhos de Economistas Profissionais}

A Lei n. 1.411, de 13 de agôsto de 1951 atribui a designação profissional de Economista aos bacharéis em ciências econômicas e aos que, embora não diplomados, forem habilitados ao exercício da profissão.

Para o exercício de cargos técnicos de economia e finanças na administração pública, nas autarquias, sociedades de economia mista, emprêsas sob intervenção governamental e nas concessionárias de serviço público é obrigatória a apresentação do diploma ou título de habilitação.

Como o órgão de contrôle e fiscalização profissional, a lei instituiu o Conselho Federal de Economistas Profissionais, com sede no Distrito Federal e jurisdição nacional e os Conselhos Regionais de Economistas Profissionais, todos constituidos mediante eleição dos órgãos de classe, com mandato de três anos.

Nos Conselhos Regionais são registrados os economistas, aos quais são expedidas carteiras profissionais, assim como as emprêsas, entidadeis ou escritórios que explorem, sob qualquer forma, atividades técnicas de economia e finanças.

Os Conselhos de Economistas Profissionais exercem o poder disciplinar sôbre a classe, arrecadam contribuições dos membros inscritos, prestam contas de sua gestão financeira ao Tribunal de Contas da União e estãn sujeitos ao contróle do Poder Judiciário, quanto à legalidade de seus atos. 


\section{F) Conselhos de Quimica}

A Lei n..$^{\circ} 2.800$, de 18 de junho de 1956 , atribuiu a fiscalização do exer cício da profisssão de quimico ao Conselho Federal de Quimica e aos Conselhos Regionais de Química, dotados de personalidade jurídica de direito público e autonomia administrativa e patrimonial. O primeiro órgão, de âmbito nacional, é constituído de um Presidente nomeado pelo Presidente da República, nove conselheiros eleitos pelos Delegados do. Conselhos Regionais e três conselheiros escolhidos pelas congregações, respectivamente, da Éscola Politécnica de São Paulo, Escola Nacional de Química e Faculdade Nacional de Filosofia. O mandato é honorífico e terá a duração de três anos. Os Conselhos Regionais são organizados segundo o modêlo de órgão nacional.

O registro obrigatório nos Conselhos Regionais, comprovado pela expcdição da carteira profissional, é condição essencial ao exercício da profissão, devendo as firmas ou emprêsas que explorem atividades no ramo fazer prova de que são atendidas por profissional habilitado e registrado.

A receita dos Conselhos de Química é constituída pela arrecadação das anuidades pagas pelos profissionais inscritos e pelas firmas ou emprêsas do ramo, sujeitas as suas contas à aprovação do Tribunal de Contas da União.

Os atos dos Conselhos Regionais são passiveis de recurso administrativo para o. Conselho Federal, cabendo ao Poder Judiciário decidir, definitivamente, sôbre a legalidade dos atos de quaisquer dêsses órgãos.

\section{Reposta ao questionário}

A exposição feita sôbre a estrutura e dinâmica dos organismos profissionais possibilita a resposta sintética ao questionário proposto pelo Relator-Geral. fissionais?

1. Quais os traços principais do regime juridico dos organismos pro-

Os organismos profissionais, que exercem função delegada do poder público (excluidos os sindicatos operários ou patronais), são, no direito brasileiro, pessoas juridicas de direito público, com personalidade juridica própria, autonomia administrativa e financeira, caracterizando-se, em sua maioria, como autarquias corporativas. A Ordem dos Advogados do Brasil que, para efeito de contrôle financeiro, não se considerou como uma autarquia, é uma pessoa jurídica sui generis, de natureza indeterminada.

Caracterizam-se tais organismos profissionais pelo poder de contrôle sôbre a respectiva categoria. A inscrição é requisito essencial ao exercício profissional, embora se trate de ato vinculado - e não discricionário. Preenchidas as condições legais, a concessão do registro se torna obrigatória. Exerce, porém, a entidade corporativa um amplo poder disciplinar, impondo aos seus associados a observância de princípios ético-profissionais, consubstanciados em atos normativos aprovados pelo próprio órgão, como, por exemplo, o Código ÉticoProfissional e o Código de Deontologia Médica.

À exceção da Ordem dos Advogados do Brasil, os demais organismos profissionais estão sujeitos ao contrôle do Tribunal de Contas da União, como 
autarquias corporativas, pela aplicação do artigo $77, n .^{\circ}$ II, da Constituição Federal, que inclui na competência dêsse órgão de fiscalização financeira o julgamento das contas dos «administradores das entidades autárquicas».

O contrôle judicial dessas pessoas jurídicas de direito público interno tem o mesmo alcance do exame exercido sôbre a legalidade dos atos de administração pública.

São criados em virtude de lei especial, que lhes regula a competência e estabelece as fontes de receita e os deveres dos membros da categoria profissional.

2. Qual a composição e as lormas de constituição dos órgãos superiotes de gestão dos organismos profiśsionais?

A direção dos organismos profissionais se desdobra em dois graus de jurisdição: órgãos locais e órgãos nacionais. Os primeiros, denominados Conselhos Regionais, exercem jurisdição territorial em um dos Estados, Territórios Federais ou Distrito Federal. Os últimos, designados como Conselho Federal, têm âmbito nacional e são, administrativamente, instância superior aos Conselhos Regionais, cujos atos podem rever, em grau de recurso.

Ambos são órgãos coletivos, de representação profissional, com mandato eletivo e gratuito.

Excepcionalmente (como no Conselho Fiscal de Engenharia e Arquitetura, Conselho Federal de Contabilidade e Conselho Federal de Quimica) o Presidente do órgão nacional é de livre nomeação do Presidente da República, sujeito ou não a mandato determinado.

A constituição dos Conselhos é, portanto, dominantemente classista, recrutando-se dentre os profissionais inscritos, segundo a. vontade das Assembléias Gerais, diretamente, ou por representação, os dirigentes dos organismos profissionats.

\section{Qual o regime financeito dêsses organismos?}

Os organismos profissionais têm como fonte principal ou mesmc exclusiva de receita as taxas pagas pelos profissionais inscritos. Não há auxilios, subvenções ou contribuições do Estado, que apenas lhes concede isenção fiscal.

A gestão financeira é controlada pelos próprios órgãos superiores das instituiçôes, cabendo, no entanto, ao Tribunal de Contas da União, exceto quanto à Ordem dos Advogados do Brasil, aprovar, anualmente, as contas dos respectivos administradores.

4. Qual a natureza e extensão dos podêtes outorgados a êsses organismos e por êles exercidos?

Os organismos profissionais recebem da lei o poder de seleção, fiscalização e disciplina da respectiva classe. $O$ exercício da profissão depende do registro no órgão regional, que é condição obrigatória e indispensável de habilitaçãu.

Também o poder disciplinar da categoria profissional é privativo dêsses organismos, que determinam as normas de conduta dos associados e aplicam penas pela violação dos deveres ético-profissionais. 
O mesmo poder de contrôle é exercido, em virtude de lei, com respeito a firmas, emprêsas ou sociedades que mantenham serviços técnicos nas especialidades sujeitas aos organismos profissionais.

5. Qual as relaçóes entre o Estado e os organismos profissionais?

Os organismos protissionais gozam de autonomia administrativa e financeira, funcionando sem a ingerência do poder público, a não ser:

a) pelo exame anual de suas contas pelo Tribunal de Contas da União (exceto, como ficou esclarecido, as da Ordem dos Advogados do Brasil);

b) pelo contrôle do Poder Judiciário, que examina os seus atos pelo mesmo processo estabelecido em lei para os atos das autoridades públicas em gerail.

Os organismos profissionais são, também, órgãos de colaboração com o Govêrno, participando, comumente, de comissões ou grupos de trabalho sôbre assuntos ligados à sua competência, propondo e defendendo, em geral, os interêsses de categoria junto ao poder público.

A Constituição Federal prevê uma forma obrigatória de colaboração, em seu artigo $124, \mathrm{n} .{ }^{\circ}$ III, assim redigido:

«o ingresso na magistratura vitalícia dependerá de concurso de provas, organizado pelo Tribunal de Justiça com a colaboração do Conselho Secional da Ordem dos Advogados do Brasil, e far-se-á a indicação dos candidatos, sempre que fôr possivel, em lista tríplice».

6. Qual a apreciação geral das relações entre o Estado e os organismos profissionais?

As informações anteriores esclarecem, à luz do direito positivo, as relações entre o Estado e os organismos profissionais indicados.

Do ponto-de-vista prático, cabe acrescentar que o Estado prestigia tais organismos, tanto pela tendência legislativa de estender êsse regime de delegação de podêres a outras categorias profissionais, como pelo acatamento dispensado à colaboração técnica das atuais entidades.

A par das organizações sindicais, bem como de associações civis de caráter representativo (institutos culturais, associações profissionais, cooperativas, associações recreativas, etc.), as classes profissionais fazem sentir os seus interêsses e aspirações junto aos podêres Executivo e Legislativo, por intermédio dos organismos ora considerados.

\section{IINIVERSIDADES}

As universidades brasileiras se distribuem em três grupos distintos:

a) estabelecimentos mantidos pela União;

b) estabelecimentos mantidos pelo poder público local (estadual ou municipal);

c) estabelecimentos privados, dependentes de reconhecimento pelo Govêrno Federal e, usualmente, por êste subvencionados. 
O conceito legal de Universidade pressupõe, pelo menos, a reunião de três estabelecimentos de ensino superior, sendo dois dêles correspondentes a Faculdade de Filosofia, Direito, Medicina ou Engenharia.

As universidades estaduais, municipais ou privadas devem ser equiparadas às federais, de modo a que os seus diplomas habilitem ao exercicio da profissão, cujo contrôle e fiscalização incurabem à União diretamente ou por meio de organismos profissionais.

A administração universitária compreende:

a) um Reitor, que é o órgão executivo da Universidade, com mandato de 3 anos, nomeado pelo respectivo Govêrno, nas universidades federais e locais e nas universidades privadas, segundo o respectivo Estatuto. A nomeação será feita mediante lista tríplice, organizada pelo Conselho Universitário, dentre os professôres das Faculdades, brasileiros natos;

b) o Conselho Universitário, órgão consultivo e deliberativo, presidido pelo Reitor e constituído de representantes dos estabelecimentos de ensino e Institutos integrantes da Universidade, além de $\mu \mathrm{m}$ representante dos docentes livres e outro do Diretório Central de Estudantes.

O Conselho Universitário exerce, como órgão deliberativo, a jurisdição superior da Universidade, aprova os orçamentos e as prestações de contas, delibera sôbre os assuntos didáticos de ordem geral e, em grau de recurso, sôbre' matéria disciplinar.

c) a Assembléia Universitária, que deve se reunir anualmente, compõe-se dos professôres de tôdas as unidades universitárias.

Cada estahelecimento universitário é administrado por:

a) um Diretor;

b) Consclho Técnico Administrativo ou Departamental;

c) congregação.

Além dêsses órgãos padrões, as Universidades, dispõem de outros, decorrentes de seus Estatutos ou de atos internos, entre os quais merecem ser destacados os seguintes:

a) Conselho de Curadores, que orienta a gestão financeira da Universidade, aprova orçamentos e prestações de contas, autoriza despesas ou acôrdos de caráter financeiro;

b) Conselho de Administração, presidido pelo Reitor e constituido pelo Conselho da Sociedade Mantenedora da Universidade Católica do Rio de Janeiro;

c) Institutos especializados, como órgãos complementares do mesmo uu de alta cultura, criados pelas próprias Universidades.

As Universidades gozam de personalidade jurídica própria e ampla autonomia administrativa, financeira, didática e disciplinar, tendo como finalidade a educação, o ensino e a pesquisa.

Os recursos financeiros são provenientes de dotações orçamentárias, atribuídos nos-orçamentos da União, Estados ou municípios, de doações e da renda de seus patrimônios próprios. 
Nos têrmos do art. 169 da Constituição Federal, anulalmente a União aplicará nunca menos de $10 \%$ (dez por cento) e os Estados, Distrito Federal e Municípios nunca menos de $20 \%$ (vinte por cento) da renda tributária na manutenção e desenvolvimento do ensino, em seus diversos graus, inclusive o superior.

Nos últimos anos tem se acentuado a federalização de universidades e estabelecimentos de ensino superior, incluindo se, attualmente, entre as Universidades federais, não sòmente a Universidade do Brasil, como as Universidades de Minas Gerais, Pernambuco (Recife), Bahia, Paraná, Ceará e Rio Grande do Sul. Entre as Universidades estaduais, também assistidas financeiramente pela União, destaca-se a Universidade de S. Paulo.

Como órgão do Ministério da Agricultura, encontra-se, ainda, a Universidade Rural, de âmbito nacional, destinada à preparação de pessoal especializado para atividades agrícolas e pastoris (especialmente através das Escolas Nacionais de Agronomia e Veterinária) e a pesquisas tendentes ao desenvolvimento científico dessas atividades.

O regime universitário brasileiro, embora intimamente vinculado, em sua estrutura financeira, aos recursos da União, caracteriza-se por apreciável autonomia administrativa e didática. Dentro das normas gerais sôbre ensino superior, cujas diretrizes são fixadas em lei federal (Constituição, art. $5 .^{\circ}, \mathrm{n} .{ }^{\circ}$ $\mathrm{XV}$, alinea $d)$, as Universidades e os estabelecimentos que as integram não se acham subordinados à ação governamental na orientação didática, como na gestão administrativa.

A liberdade de cátedra figura entre os principios constitucionais obrigatórios (Constituição, art. 168, n. VIII) e representa uma tradição no direito público brasileiro, como uma das formas essenciais da livre manifestação do pensamento.

A escolha dos professôres catedráticos, tanto no ensino oficial, como no ensino privado, é feita sempre mediante concurso de provas e títulos (Constituição, art. $168, n 0^{\circ}$ II). A nomeação é feita em caráter vitalício, sòmente podendo ser afastado o professor mediante aposentadoria compulsória aos 70 anos de idade, ou en virtude de sentença judiciária. 